\title{
An automated method of psychiatric treatment planning
}

\author{
CHRIS E. STOUT \\ Forest Hospital and Foundation, Des Plaines, Illinois
}

\begin{abstract}
Several procedures used to develop automated psychodiagnostic methods have been successful. This paper presents the next step toward a method of automating the treatment planning of psychiatric patients.
\end{abstract}

Accurate diagnosis is the sine qua non of appropriate treatment. Various methods of automated psychodiagnostics have been reported (Stout, 1988, 1990; Stout \& Scheramic, 1989). Such methods have demonstrated how to use programming languages and preexisting packages (e.g., Aston-Tate's dBASE) to develop systems that aid in tutorials and in teaching the decision-making process within the Diagnostic and Statistical Manual (DSM-III, American Psychiatric Association, 1980). There are also systems that utilize a database structure to conduct differential psychodiagnoses with DSM-III-R (APA, 1987) and to engage in differential diagnostics between physical disorders mimicking psychiatric disorders. The latter systems may be used in various other ways. For example, in addition to diagnostic suggestions or "rule-outs," a user can access symptom definitions, list symptoms for specific disorders (as well as listing disorders for specific symptoms), or provide updates and append the database as new information becomes available.

The area of mental health/clinical practice applications has long been one of automated development and innovation. Numerous researcher/programmers (Hirshfeld, Spitzer, \& Miller, 1974; Overall \& Hollister, 1964; Spitzer \& Endicott, 1968) have developed various psychodiagnostic systems, but little exists in this area concerning the "next step" after diagnostic formulation-that is, treatment planning.

The effectiveness of psychiatric and psychological treatment today depends on time and cost. In today's health care system, length of stay or total number of sessions is limited for both inpatients and outpatients. Thus, diagnostic aid with accuracy and speed is a benefit. It stands to reason that treatment planning could concomitantly benefit from an increase in accuracy (completeness) and a decrease in time.

The problem is that a primary therapist is not infallible. He/she may miss a treatment component here and there, not out of negligence or naïveté, but possibly by being focused on other areas of a patient's dysfunctions

Correspondence should be addressed to C. E. Stout, Forest Hospital and Foundation, 555 Wilson Lane, Des Plaines, IL 60016-4794. or by not having specialized expertise or knowledge concerning all types of interventions. It simply is not possible to be equally conversant or expert in all types of treatments, with all types of patients, with all types of diagnoses, or with all types of symptoms.

In response to this need, I developed a type of "treatment matrix" using a spreadsheet (Lotus 1-2-3). Lotus was chosen because it is relatively inexpensive, well known, widely used/familiar, and well supported.

The matrix is composed of over $\mathbf{4 5}$ different but commonly occurring diagnostic categories (DSM-III-R, APA, $1987)$ on the $y$-axis. The $x$-axis contains diagnosis, symptoms, medical evaluation, medical treatment, pharmacotherapy, behavioral therapy, cognitive therapy, family therapy, and psychodynamic therapy. The resultant cells are completed by reference to state-of-the-art resources and expert therapists.

The program is easy to use. After pulling up the file using standard Lotus 1-2-3 commands, the user moves the cursor to the diagnostic category or series of symptoms that match with the case being evaluated. The user then selects from any or all of the seven different therapies listing the specific treatment(s) recommendation(s).

Consider a typical example. Prior to a patient staffing, the user would pull up the diagnosis and/or associated symptoms and print out a series of recommended treatments. This printout would then go to the staff, and the treatment team would then pick or delete the recommended therapies by virtue of the "goodness of fit" to the patient. Other treatments could always be added. The software provides improved consistency between staff and confidence that most treatment options have been considered before a treatment decision.

The program runs on any MS-DOS-based system. A hard disk drive is desirable but not necessary. Its design permits the program to be easily modified by the user and requires no programming knowledge other than familiarity with Lotus 1-2-3. It can be used in both diagnostic and treatment clinical courses at the graduate, intern, and postdoctoral levels. Although it was developed for use in an inpatient psychiatric setting, it can be used in outpatient clinics. It provides assistance to new staff on the treatment team as well as to "old-timers." Future develop- 
ments could include empirical data on expected treatment duration, outcome potential, iatrogenic effects or side effects, and associated cost.

To receive a free copy of the software, send a selfaddressed, stamped container with a 3.5-in. formatted disk to the author.

\section{REFERENCES}

American Psychintric Association (1980). Diagnostic and statistical manual of mental disorders (3rd ed.). Washington, DC: Author. american Psychiatric Associntion (1987). Diagnostic and statistical manual of mental disorders (rev. ed.). Washington, DC: Author. Hirshfeld, R., Spitzer, R. L., Miller, R. G. (1974). Computer diagnosis in psychiatry: A Bayes approach. Journal of Nervous \& Mental Diseases, 158, 339-407.

Overall, R. L., Hollister, L. E. (1964). Computer procedures for psychiatric classification. Joumal of the American Medical Association, $18,583-585$.

SPITZER, R. L., \& ENDICotT, J. (1968). DIAGNO: A computer program for psychiatric diagnoses utilizing differential diagnostic procedure. Archives of General Psychiatry, 18, 746-796.

Stout, C. E. (1988). Personal computer software for teaching differential psychodiagnostics. Behavior Research Methods, Instruments, \& Computers, 20, 106-107.

STout, C. E. (1990). Software development for the nonprogrammer: An instructional clinical example. Behavior Research Methods, Instruments, \& Computers, 22, 200-201.

Stout, C. E., \& Scheramic, M. (1989). Innovative uses of existing software in the teaching of psychodiagnostics. Behavior Research Methods, Instruments, \& Computers, 21, 187-188. 